\title{
Investigating the Employed Married Women's Awareness Level of Marriage Rights: Case Study -- Neiriz, Iran
}

\author{
Zainab Ghadar Band Shirazifard ${ }^{1} \&$ Ali Edalati ${ }^{1}$ \\ ${ }^{1}$ Sociology Department, Payame Noor University, Iran \\ Correspondence: Ali Edalati, Sociology Department, Payame Noor University, Iran. Tel: 98-91-7620-6457. \\ E-mail: alisq2008@yahoo.com
}

Received: March 16, 2012

doi:10.5539/ass.v8n8p172

Accepted: April 12, $2012 \quad$ Published: July 1, 2012

URL: http://dx.doi.org/10.5539/ass.v8n8p172

\begin{abstract}
This survey is aimed to investigate the employed married women's degree of awareness of the marriage rights. Sample includes 100 employed married women of Neiriz city who were selected through randomized sampling. The Morgan's and Krejcie's table was used in order to calculate the sample size. From the results, it becomes clear that there is a meaningful relationship between the degree of awareness of the marriage rights. It has also shown that there is a significant relationship between age and awareness of the marriage right; it shows a positive relation between income awareness of the marriage right. It has also shown that there is no relationship between marriage age and the women's awareness of marriage rights. Finlay result shows a significant relation between use of mass media and awareness of the marriage right. Moreover, in order to increase the level of women's awareness of their rights, the role of mass media should be made clear in the societies. The findings highlight the need for screening and identification of other factors and variables in the family and society in which women are growing.
\end{abstract}

Keywords: women, women right, women awareness, Iran

\section{Introduction}

Women are the basic elements of the families. Their awareness in various fields helps the substructures families - of the society to be more stable. Under the influence of being aware of marriage rights, the oppression of the women is decreased and their satisfaction from married life is increased. Women's awareness depends on a variety of factors including economic, psychological, social, cognitive and political dimensions (Stromquist, 1995). Awareness of marriage rights causes persons to marry consciously. Therefore, unwanted consequences of married life are decreased through being aware of marriage rights. Awareness of marriage rights affects on the stability of family and society. Marriage refers to a social and legal custom through which the union of a couple is formed (Mohseni and Poor Reza Anvar, 2003). The family stability depends on the basic rules. Today, "Human right is one of the main issues which emphasizes mainly on the women rights and denies the women discrimination. The main problem of the modern societies is unawareness of human rights. Unawareness of such rights causes them to be useless. Doddle Veneering believes that peace is rooted in human rights. Sylvan argues that family rights guarantee the family stability and these rights are strongly paid attention by sociologists.

\section{Review of Literature}

In his study, "Investigating the couples' awareness of their rights and its effect on the family connections in Tehran", Malik (1994) concluded that the couples' awareness of their legal responsibilities and rights doesn't have a positive influence on their family connections. Moreover, because of the increase of age, some persons ignore the rights of married life. Educational degree affects, too, on the couple's awareness of their legal rights. In other words, those who have higher educational degree know the rights of married life better. Most of the married people are not informed from the contents of marriage contract, including the legal rights of the couples. The Jamshidian's (2003) study "investigating the Isfahan's couples' attitudes and level of awareness of family rights and its relationship to the family stability", is a landmark in the research on the couples' awareness of their rights. In his descriptive - scientific study, Jamshidian selected 312 of divorced, divorcing and non-divorced persons as the sample. He concluded that the divorcing and divorced persons have different attitudes toward the family rights, compared to the non-divorced ones. Also, they are well aware of family rights. There is a direct 
relationship between the time of marriage and the level of awareness. Sarikhani (2009) studied the level of awareness of muslim working women toward their rights in islam: a case study in government offices in Mysore. India. She used simple random sampling technique in the selection of sample for her study. Sample was consisted of 146 Muslim women who worked in government office sectors. The results revealed that level of awareness of Muslim working women is average level, but they can not use them in their true life. In another study Shahnaj Parveen (2007) studied the social status of rural women and their level of gender awareness (GA) in three villages of Bangladesh. Data were collected from 156 respondents through group discussions and personal interviews from December 2002 to April 2003. Women's social status and GA was determined following the Likert scale method. Finding reveals that personal income and physical beauty of rural women are the most important factors determining a higher social status while women with distressed conditions including mental and physical disabilities were found to have a lower social status. Results show that among ten pre-selected attributes relating to gender, the respondents were able to recognize gender discrimination with respect to domestic violence, community participation, inheritance of property rights, timing of marriage and divorce rights.

The Ghasim Zadeh's article (2001) "The straits of women's' life", investigated the women's awareness of their legal rights. The role of Carolyn Volga's \& John Paul's survey, "the role of money, power and sexuality in marriage", is an example for the search on the relationship between money, power and marriage. In this survey, the sample was interviewed in order to gather data. In sum, results showed that those having more income play a key role in the family affairs and the employed women play a central role in decision - makings, compared to the unemployed ones. On the other hand, the more inequality in making money, the more the couples' inequality is increased. In other words, the sexuality inequality is rooted in the class distinctions. For example, the men who have more efficient income take a more active role in decision - makings. Sexuality inequality of the couples is under the influence of income distribution (Croly Vulgar, Quoted from Gorgy, 2004). Investigating the sexuality gap of Canadians in 1865 - 1990, Uri Johan used Liker's test and past studies in order to evaluate the attitudes of women toward the sexuality gap. From the results, it become clear that the increase of educational degree, participation in entrepreneurial activities and the growth of delivering movements of women (especially the second wave of Feminism) affect on the traditional roles of women and their awareness. Moreover, the mentioned factors affect increasingly on the creation of public gap. In other words, the difference between the women's attitudes is under the influence of their awareness and traditional roles.

\section{Methodology}

This is a descriptive survey in which 100 employed married women of Neiriz were selected as the sample. Some of the women were interviewed and some others were asked to complete the questionnaires in order to gather data. The Krejcie's \& Morgan's (1970) table was used in order to calculate the sample volume. In order to analyze data, the descriptive and comprehensive statics were used. The frequency distribution table and polygon chart were used in descriptive part and the square test was used in comprehensive part.

\section{Results}

As seen in the Table 1, the most frequency percent (\%27) is related to the 30-35-year old persons and the lowest number (\%2) is related to the 50-55- year old ones. Moreover, $\% 9$ of the respondents are $20-25$ years old, $\% 19$ are $25-30$ years old, $\% 13$ are 35-40 years old, $\% 20$ are $40-44$ years old and $\% 10$ are $45-49$ years old. Because the women are employed, it is not important them to be below 20 years old or up to 55 years old.

Table 1. Frequency distribution of the respondents based on their age criterion

\begin{tabular}{lll}
\hline Age & Frequency & Percent \\
\hline $20-24$ & 9 & 9 \\
$25-29$ & 19 & 19 \\
$30-34$ & 27 & 27 \\
$35-39$ & 13 & 13 \\
$40-44$ & 20 & 20 \\
$45-49$ & 10 & 10 \\
$50-54$ & 2 & 2 \\
Total & 100 & 100 \\
\hline
\end{tabular}

As shown in the Table 2, the most frequency percent (\%11) is related to the ages 20,23 and 25 and the lowest 
frequency percent is related to the 12 and 15 years old group. Moreover, the frequency percents of the participants' marriage age are as the following: $\% 3$ are 16 years old, $\% 2$ are 17 years old, $\% 7$ are 18 years old, $\% 9$ are 19 years old, $\% 7$ are 21 years old, $\% 10$ are 22 years old, $\% 10$ are 24 years old, $7 \%$ are 26 years old, $\% 5$ are 22 years old, $\% 2$ are 28 years old, $\% 5$ are 27 years old and $\% 2$ are 30 years old. Therefore, during recent decades, the women's marriage age has increased because of the increase of educational degree.

Table 2. Frequency distribution of the respondents based on the marriage age

\begin{tabular}{lll}
\hline Marriage age & frequency & $\mathbf{\%}$ \\
\hline 12 & 1 & $\mathbf{1}$ \\
13 & 0 & $\mathbf{0}$ \\
14 & 0 & $\mathbf{0}$ \\
15 & 1 & $\mathbf{1}$ \\
16 & 3 & $\mathbf{3}$ \\
17 & 2 & $\mathbf{2}$ \\
18 & 7 & $\mathbf{7}$ \\
19 & 9 & $\mathbf{9}$ \\
20 & 11 & $\mathbf{1 1}$ \\
21 & 7 & $\mathbf{7}$ \\
22 & 10 & $\mathbf{1 0}$ \\
23 & 11 & $\mathbf{1 1}$ \\
24 & 10 & $\mathbf{1 0}$ \\
25 & 11 & $\mathbf{1 1}$ \\
26 & 7 & $\mathbf{7}$ \\
27 & 5 & $\mathbf{5}$ \\
28 & 2 & $\mathbf{2}$ \\
29 & 0 & $\mathbf{0}$ \\
30 & 2 & $\mathbf{2}$ \\
Null & 1 & $\mathbf{1}$ \\
Total & 100 & $\mathbf{1 0 0}$ \\
\hline
\end{tabular}

As illustrated in Table 3, the most frequency percent (\%47) is related to the income level of 200-300 000 Rails and the lowest ratio (\%2) is related to the income level 300-400000 Rails a month. Rather than the above mentioned, the 5,26 and 20 frequency percents are respectively related to the incomes 50-100000 and 100-200000 Rails in month.

Table 3. The respondents' frequency percent based on their incomes

\begin{tabular}{lll}
\hline Income & frequency & $\%$ \\
\hline $50-100$ & 5 & 5 \\
$100-200$ & 26 & 26 \\
$200-300$ & 47 & 47 \\
$300-400$ & 2 & 2 \\
Null & 20 & 20 \\
total & 100 & 100
\end{tabular}

As seen in the Table 4, \%39 of the respondents use frequently form mass media, \%34 of them use more frequently from mass media and $\% 27$ uses them lowly.

Using square test, the relationship between the independent and dependent variables is studied. This test is used because the scale of measurement is the best one for non - parametric statics of square test. 
Table 4. Respondent's frequency percent based on the use of mass media

\begin{tabular}{lll}
\hline Communication media & frequency & $\%$ \\
\hline Strongly high & 34 & 34 \\
High & 39 & 39 \\
Low & 27 & 27 \\
Strongly low & 0 & 0 \\
total & 100 & 100 \\
\hline
\end{tabular}

As we can see in Table 5 , since $\mathrm{x}^{2}=30 / 57>\alpha=\% 5, \mathrm{DF}=18$, this hypotheses is accepted. Therefore, this is to say that there is a direct relationship between the women's level of awareness and their age.

Table 5. The relationship between age and the women's' level of awareness of marriage rights (Hypotheses 1)

\begin{tabular}{llllllllll}
\hline $\begin{array}{l}\text { Level of } \\
\text { awareness }\end{array}$ & Fo & Fe & Fo & Fe & Fo & Fe & Fo & Fe & total \\
\hline Age & - & $0 / 27$ & 1 & $1 / 44$ & 3 & $4 / 77$ & 5 & $2 / 52$ & 9 \\
$20-24$ & - & $0 / 57$ & 5 & $3 / 04$ & 11 & $10 / 07$ & 3 & $6 / 03$ & 19 \\
$25-29$ & - & $0 / 81$ & 3 & $4 / 8$ & 17 & $17 / 96$ & 7 & $9 / 25$ & 27 \\
$30-34$ & 1 & $0 / 39$ & 2 & $2 / 84$ & 7 & $6 / 89$ & 3 & $3 / 65$ & 13 \\
$35-39$ & - & $0 / 6$ & 1 & $3 / 77$ & 11 & $10 / 6$ & 8 & $5 / 6$ & 20 \\
$40-44$ & 2 & $0 / 3$ & 4 & $1 / 6$ & 3 & $5 / 3$ & 1 & $2 / 8$ & 10 \\
$45-49$ & - & $0 / 06$ & - & $0 / 32$ & 1 & $10 / 6$ & 1 & $0 / 56$ & 2 \\
total & 3 & 3 & 16 & 16 & 53 & 53 & 28 & 28 & 100 \\
\hline
\end{tabular}

Table 6 shows, $x^{2}=17 / 77<28 / 87, \mathrm{DF}=18, \alpha=\% 5$, this is to say that there is no direct relationship between marriage age and the women's awareness of marriage rights.

Table 6. The relationship between marriage age and the women's level of awareness of marriage rights

$$
\text { 8-12 12-16 } 16-20 \quad 20-24
$$

\begin{tabular}{|c|c|c|c|c|c|c|c|c|c|}
\hline $\begin{array}{l}\text { Level of } \\
\text { awareness }\end{array}$ & Fo & $\mathrm{Fe}$ & Fo & $\mathrm{Fe}$ & Fo & $\mathrm{Fe}$ & Fo & $\mathrm{Fe}$ & total \\
\hline \multicolumn{10}{|l|}{ Age } \\
\hline $12-15$ & - & $/ 03$ & - & $/ 16$ & 1 & $/ 53$ & - & $/ 28$ & 1 \\
\hline $15-18$ & - & $/ 18$ & 1 & $/ 96$ & 4 & $3 / 18$ & 1 & $1 / 64$ & 6 \\
\hline $18-21$ & 1 & $/ 78$ & 3 & $4 / 16$ & 16 & $13 / 78$ & 6 & $7 / 28$ & 26 \\
\hline $21-24$ & 1 & $/ 89$ & 5 & $4 / 64$ & 14 & $15 / 37$ & 3 & $8 / 12$ & 29 \\
\hline 24-27 & 1 & $/ 84$ & 2 & $4 / 48$ & 16 & $14 / 84$ & 3 & $7 / 84$ & 28 \\
\hline $27-30$ & - & $/ 27$ & 5 & $1 / 44$ & 2 & $4 / 77$ & 2 & $2 / 52$ & 9 \\
\hline $\begin{array}{l}\text { Without } \\
\text { answer }\end{array}$ & - & $/ 03$ & - & $/ 16$ & - & $/ 53$ & 1 & $/ 28$ & 1 \\
\hline total & 3 & 3 & 16 & 16 & 53 & 53 & 28 & 28 & 100 \\
\hline
\end{tabular}

Table 7 shows, $x^{2}=24 / 43>x^{2}=21 / 03, d_{f}=12$ and $\alpha=\% 5$, hypothesis 4 is accepted. Therefore, this is to say that there is a direct relationship between the women's awareness of marriage rights and their income.

Table 7. The relationship between income and the women's awareness of marriage rights

$8-12$

$12-16$

$16-20$

$20-24$

\begin{tabular}{llllllllll}
\hline $\begin{array}{l}\text { Level of } \\
\text { awareness }\end{array}$ & Fo & Fe & Fo & Fe & Fo & Fe & Fo & Fe & total \\
\hline $100-300$ & $\mathbf{0}$ & $/ 15$ & 0 & 18 & 2 & $2 / 65$ & 3 & $1 / 4$ & 5 \\
$100-200$ & $\mathbf{0}$ & $/ 78$ & 7 & $14 / 16$ & 14 & $13 / 78$ & 5 & $7 / 28$ & 26 \\
$200-300$ & $\mathbf{0}$ & $1 / 41$ & 4 & $7 / 52$ & 26 & $24 / 91$ & 17 & $13 / 16$ & 47 \\
$300-400$ & $\mathbf{0}$ & $/ 06$ & 0 & 132 & 2 & $1 / 06$ & 0 & 156 & 2 \\
$\begin{array}{l}\text { Without } \\
\text { answer }\end{array}$ & $\mathbf{3}$ & 16 & 5 & $3 / 2$ & 9 & $10 / 6$ & 3 & $5 / 6$ & 20 \\
total & $\mathbf{3}$ & 3 & 16 & 16 & 53 & 53 & 28 & 28 & 100 \\
\hline
\end{tabular}

Table 8 shows, $x^{2}=27 / 171>x^{2}=21 / 03, d_{f}=12$ and $\alpha=\% 5$, this hypothesis is accepted. Therefore, this is to say that there is a direct relationship between mass media and the women's awareness of marriage rights. 
Table 8 . The relationship between the use of mass media and the women's awareness of marriage rights

\begin{tabular}{llllllllll} 
& \multicolumn{2}{c}{$8-12$} & \multicolumn{2}{c}{$12-16$} & \multicolumn{2}{c}{$16-20$} & \multicolumn{2}{c}{$20-24$} \\
\hline $\begin{array}{l}\text { Level of } \\
\text { awareness }\end{array}$ & Fo & Fe & Fo & Fe & Fo & Fe & Fo & Fe & total \\
\hline $\begin{array}{l}\text { Strongly } \\
\text { high }\end{array}$ & $\mathbf{2}$ & $1 / 65$ & 5 & $8 / 88$ & 28 & $29 / 15$ & 20 & $15 / 4$ & 55 \\
High & $\mathbf{2}$ & $3 / 84$ & 20 & $21 / 81$ & 71 & $83 / 28$ & 34 & $35 / 84$ & 128 \\
Null & $\mathbf{6}$ & $5 / 07$ & 35 & $27 / 04$ & 93 & $89 / 57$ & 35 & $47 / 32$ & 169 \\
Low & $\mathbf{8}$ & $5 / 67$ & 27 & $29 / 44$ & 101 & $97 / 52$ & 48 & $51 / 52$ & 184 \\
Strongly & - & $1 / 92$ & 9 & $10 / 24$ & 25 & $23 / 92$ & 31 & $17 / 92$ & 64 \\
low & & & & & & & & & \\
total & $\mathbf{1 8}$ & 18 & 96 & 96 & 318 & 318 & 168 & 168 & 600 \\
\hline
\end{tabular}

\section{Conclusion}

This is a survey in which 100 employed married women of Neiriz were randomly selected as the sample. Using some questionnaires, data was gathered. The gathered data was analyzed using descriptive and deductive statics. From these results, there is a direct relationship between the women's income, age and the use of mass media and their awareness of marriage rights. But there is no relationship between the women's marriage age and their awareness of marriage rights. Based on the above mentioned, the followings are suggested in order to improve the married life: To make the women aware of their marriage rights through mass media and related organizations such as schools. To add some credits to schools and universities in order to train the girls. To make the women aware of their rights through publication of brushers and TV programs To add training periods to deliberative classes before the marriage To make aware the families and make cultures in order to help the girls to be aware of married life rights.

\section{Limitations}

Women pause to answer the questions such as "How old are you?" Data gathering spends much time because the employed women's rest time is limited.

\section{References}

Gorge, A. (2004). Investigating the effect of economic and social factors on 25-45 years old Shirazi women's attitudes toward the sexuality inequalities. Shiraz: Shiraz university.

Jamshidian, A. (2003). Investigating the relationship between the Isfahan's couple's attitudes and awareness of family rights and the family stability (2nd ed.). Isfahan: Islamic culture and guiding.

Krejcie, R. V., \& Morgan, D. W. (1970). Determining sample size for research activities. Educational and Psychological Measurement, 30(607-610).

Mohseni , M., \& Poor Reza Anvar, A. (2003). Marriage and family in Iran. Tehran: Arvan Publisher.

Sarikhani, N. (2009). Level of Awareness of Muslim Working Women toward Their Rights in Islam: A Case Study in Government Offices in Mysore. Jornal of Soc Sci, 18(3), 163-171.

Shahnaj Parveen. (2007, November). Gender Awareness of Rural Women in Bangladesh. Journal of International Women's Studies, 9(1).

Stromquist, P.N. (1995). The Theoretical and Practical Bases for Empowerment. In C. Medel-Añonuevo (Ed.), Women, Education and Empowerment: Pathways Towards Autonomy (pp. 13-22). Hamburg, Germany: UNESCO Institute for Education. 